Article

\title{
Rapid Removal of Azophloxine via Catalytic Degradation by a Novel Heterogeneous Catalyst under Visible Light
}

\author{
Di Wu, Kequan Xia, Chengzhu Fang, Xuegang Chen * ${ }^{-10}$ and Ying Ye \\ Ocean College, Zhejiang University, Zhoushan 316021, China; w655460@163.com (D.W.); \\ KequanXia@163.com (K.X.); fangczwork@163.com (C.F.); gsyeying@zju.edu.cn (Y.Y.) \\ * Correspondence: chenxg83@zju.edu.cn; Tel.: +86-580-209-2326; Fax: +86-580-209-2891
}

Received: 10 December 2019; Accepted: 16 January 2020; Published: 19 January 2020

\begin{abstract}
Azo dyes are the most widely used synthetic dyes in the printing and dyeing process. However, the discharge of untreated azo dyes poses a potential threat to aqueous ecosystems and human health. Herein, we fabricated a novel heterogeneous catalyst: activated-carbon-fiber-supported ferric alginate (FeAlg-ACF). Together with peroxymonosulfate (PMS) and visible light, this photocatalytic oxidation system was used to remove an azo dye-azophloxine. The results indicated that the proposed catalytic oxidation system can remove $100 \%$ of azophloxine within $24 \mathrm{~min}$, while under the same system, the removal rates were only $92 \%$ and $84 \%$ when ferric alginate was replaced with ferric citrate and ferric oxalate, respectively, which showed the superiority of FeAlg-ACF. The degradation of azophloxine is achieved by the active radicals $\left(\mathrm{SO}_{4}{ }^{\bullet-}\right.$ and $\left.\bullet \mathrm{OH}\right)$ released from PMS and persistent free radicals from activated carbon fiber. Moreover, due to ferric alginate's highly intrinsic photosensitivity, visible radiation can further enhance the ligand-to-metal charge transfer (LMCT) processes. After $24 \mathrm{~min}$ of treatment, the total organic carbon of the azophloxine solution $(50 \mu \mathrm{mol} / \mathrm{L})$ decreased from $1.82 \mathrm{mg} / \mathrm{L}$ to $79.3 \mu \mathrm{g} / \mathrm{L}$ and the concentration of nitrate ions increased from $0.3 \mathrm{mg} / \mathrm{L}$ to $8.6 \mathrm{mg} / \mathrm{L}$. That is, up to $93.5 \%$ of azophloxine molecules were completely degraded into inorganic compounds. Consequently, potential secondary contamination by intermediate organic products during catalytic degradation was prohibited. The azophloxine removal ratio was kept almost constant after seven cycles, indicating the recyclability and longevity of this system. Furthermore, the azophloxine removal was still promising at high concentrations of $\mathrm{Cl}^{-}, \mathrm{HCO}_{3}{ }^{-}$, and $\mathrm{CO}_{3}{ }^{2-}$. Therefore, our proposed system is potentially effective at removing dye pollutants from seawater. It provides a feasible method for the development of efficient and environmentally friendly PMS activation technology combined with FeAlg-ACF, which has significant academic and application value.
\end{abstract}

Keywords: peroxymonosulfate; ferric alginate; activated carbon fiber; visible radiation; heterogeneous photocatalysis

\section{Introduction}

Azo dyes are widely used in the printing and dyeing industries. However, about $10 \%-15 \%$ of residual azo dyes are discharged into the environment without treatment, which causes severe environmental pollution and poses hazards for aqueous organisms and human health [1-4]. Therefore, it is of great practical significance to develop efficient and environmentally friendly treatment methods for dye wastewater. Among many water pollution treatment methods, Fenton-like oxidation technology, as a typical advanced oxidation technology, has been widely favored by researchers due to its advantages of high efficiency, environmental friendliness, and circularity [5-9]. The amount of 
reactive oxygen species (ROS) is an important factor for the catalytic efficiency of the photocatalytic system, especially in relatively mild conditions [10-13]. Peroxymonosulfate (PMS) is a widely used material to provide ROS to remove a variety of refractory organic pollutants in environmental remediation $[14,15]$. PMS can be activated to produce $\bullet \mathrm{OH}$ and $\mathrm{SO}_{4}{ }^{\bullet-}$ by transition metal ions with advantages of simple reaction conditions, rapid reaction rate, and low cost [16-18].

Studies have shown that Fe(III) easily forms complexes with carboxyl groups [19-22]. These complexes are often photoactive and can be decomposed under light to produce a variety of active species (Equations (1)-(7)):

$$
\begin{gathered}
\mathrm{RCOO}-\mathrm{Fe}(\mathrm{III})+\mathrm{hv} \rightarrow \mathrm{Fe}(\mathrm{II})+\mathrm{RCOO} \\
\mathrm{RCOO} \bullet \rightarrow \mathrm{R} \bullet+\mathrm{CO}_{2} \\
\mathrm{R} \bullet+\mathrm{Fe}(\mathrm{II}) \rightarrow \mathrm{Fe}(\mathrm{III})+\text { products } \\
\mathrm{R} \bullet+\mathrm{O}_{2} \rightarrow \mathrm{O}_{2}^{-} \bullet+\text { products } \\
\mathrm{H}^{+}+\mathrm{O}_{2}^{-} \bullet \rightarrow \mathrm{HO}_{2} \bullet \\
\mathrm{HO}_{2} \bullet+\mathrm{HO}_{2} \bullet \rightarrow \mathrm{H}_{2} \mathrm{O}_{2}+\mathrm{O}_{2} \\
\mathrm{HO}_{2} \bullet+\mathrm{H}^{+}+\mathrm{Fe}(\mathrm{II}) \rightarrow \mathrm{H}_{2} \mathrm{O}_{2}+\mathrm{Fe}(\mathrm{III}) .
\end{gathered}
$$

In analogy to other Fe(III)-carboxylate complexes, such as ferric citrate and ferric oxalate [23-25], ferric alginate (Fe-Alg) could initiate the generation of a series of active oxygen species and $\mathrm{Fe}(\mathrm{II}) / \mathrm{Fe}(\mathrm{III})$ ions by the ligand-to-metal charge transfer (LMCT) under light irradiation [26]. However, ferric citrate and ferric oxalate are greatly affected by the $\mathrm{pH}$ value. When the $\mathrm{pH}$ value is greater than 4 , both the ferric citrate and ferric oxalate complexes are converted into $\mathrm{Fe}_{2} \mathrm{O}_{3} \bullet n \mathrm{H}_{2} \mathrm{O}$ amorphous precipitation, leading to the decrease or disappearance of the optical activity of the system [27].

As an iron-based photocatalyst, the Fe-Alg complex is made by cross-linking the multivalent $\mathrm{Fe}(\mathrm{III})$ with natural, nonhazardous, and edible polysaccharide alginate [28]. There are a large number of carboxyl groups in the molecular structure of alginate. Studies have shown that some carboxyl acids can produce active reducing free radicals by self-photolysis, and there are also a large number of hydroxyl groups. Thanks to their unique gelling properties, alginates can react with metal ions to form stable organic-inorganic hybrid composite materials, which may be promising for applications in the environmental purification and remedy areas [29-33].

Although iron alginate gel beads that can increase the $\mathrm{pH}$ range of Fenton-like catalysts have been studied in recent years [34], there are still some unresolved difficulties, such as tedious preparation process, non-reusability, and hydrolysis under a strong base [35-37]. Therefore, it is necessary to construct a heterogeneous catalytic system with Fe-Alg as the active center to accelerate the process of metal-ligand charge transfer and improve the stability of materials, so as to improve the degradation efficiency of dye wastewater.

A suitable carrier is also essential for a catalytic system. The most commonly used heterogeneous catalytic carriers are zeolite, resin, clay, molecular sieve, activated carbon, etc. [38-41]. Among them, activated carbon has attracted extensive attention due to its large specific surface area and strong adsorption performance. However, activated carbon is generally powdered or granular, and there are still problems such as separation and regeneration difficulties between catalyst and reaction medium. Compared with powdered or granular activated carbon, activated carbon fiber (ACF) has 
more excellent properties [42]. Due to its microporous structure, ACF usually shows a specific surface area of up to $3000 \mathrm{~m}^{2} / \mathrm{g}$ with an average value of $1000-1500 \mathrm{~m}^{2} / \mathrm{g}$ [43-45]. The outer surface area of ACF is two orders of magnitude higher than the internal surface area. Therefore, ACF could provide high adsorption efficiency for the photocatalytic system. The adsorption ability of ACF is stronger than that of activated carbon for some macromolecules or particles [46,47]. Furthermore, the surface of ACF contains abundant oxygen-bearing groups, and its surface structure can be modified to further improve its adsorption performance [48,49]. On the other hand, ACF could provide large amounts of persistent free radicals (PFRs) for Fe, which helps to further accelerate the LMCT process and reduce $\mathrm{Fe}(\mathrm{III})$ to the $\mathrm{Fe}(\mathrm{Il})$ state $[15,50]$. Therefore, when transition metals such as $\mathrm{Fe}, \mathrm{Cu}, \mathrm{Co}$, and $\mathrm{Ni}$ are loaded on the surface of ACF, through ACF's inherent PFRs starting the electron transfer in catalytic oxidation and continuing to provide electrons, those transition metals can accelerate high transition metal reduction reaction with visible light photocatalytic synergy, activate the PMS to produce ROS, and thus degrade organic dyes.

In this work, we report a novel photocatalytic oxidation system (FeAlg-ACF/PMS/visible light) for the first time. The ACF serves as the carrier, and PMS provides oxidants; Fe-Alg was loaded on the surface of ACF via a simple impregnation method to create a Fenton-like catalyst, FeAlg-ACF. We assessed the removal of azo dyes by this novel system and investigated the optimum treatment conditions. In addition, we propose the potential degradation mechanism of azo dyes by FeAlg-ACF/PMS under visible light.

\section{Results and Discussions}

\subsection{Characteristics of the As-Prepared Catalyst}

The surface topography of ACF and FeAlg-ACF was evaluated by SEM. Figure 1a,c respectively shows the surface morphologies of ACF and FeAlg-ACF at 5000 times magnification. The iron alginate was densely and uniformly distributed on the surface of the ACF. In addition, the iron content of the precipitated solution after the formation of the heterogeneous catalyst FeAlg-ACF was determined to be only $0.026 \%$ by XRF. This indicated that iron had been successfully loaded onto the ACF. The microscopy results suggested that Fe-Alg particles were densely and uniformly cross-linked and distributed on the surface of ACF. At high magnification, as shown in Figure 1b,d, the loaded Fe-Alg particles showed rod-like shapes with a width of about $40 \mathrm{~nm}$ and a length of $60 \mathrm{~nm}$.
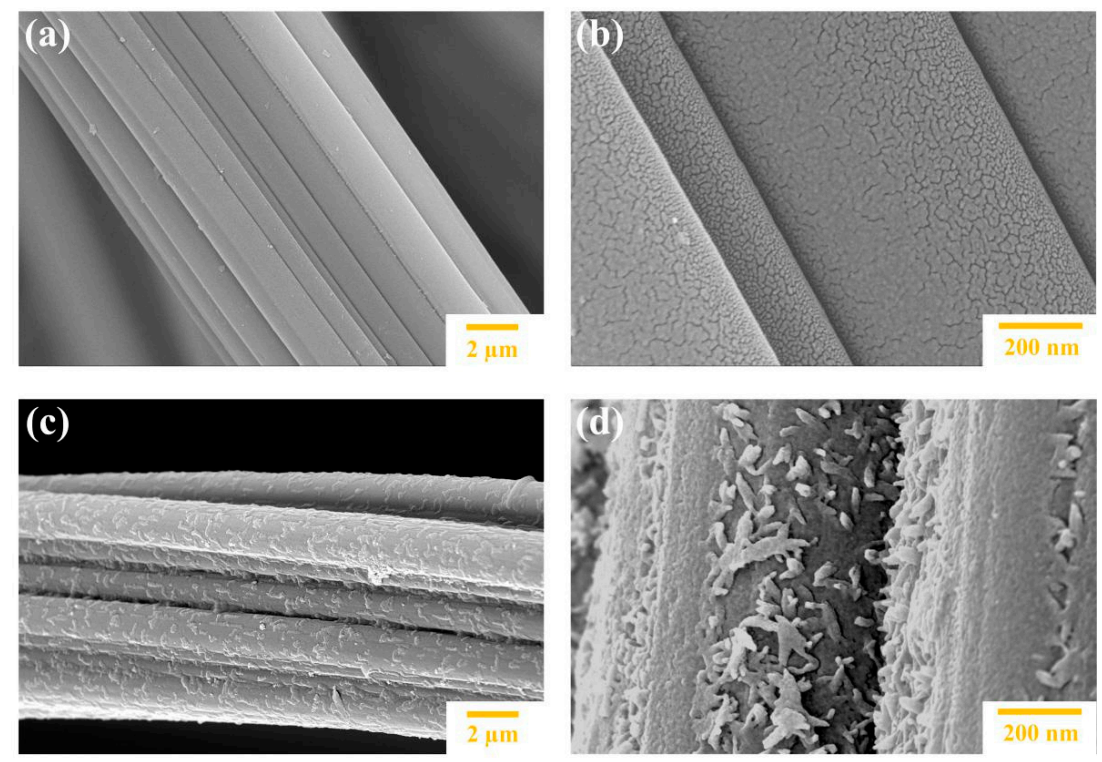

Figure 1. SEM images of activated carbon fiber (ACF) at 5000× (a) and 45,000× (b) magnification, as well as the FeAlg-ACF catalyst at $5000 \times($ c) and $45,000 \times(d)$ magnification. 


\subsection{Dye Removal by Fe-Alg Catalyst}

The removal of azophloxine by different systems was investigated in the dark and in visible light. As shown in Figure 2A, ACF and FeAlg-ACF removed $8 \%$ and $10 \%$ of azophloxine, respectively, after $24 \mathrm{~min}$ in dark conditions, suggesting that the adsorption of azophloxine by ACF and FeAlg-ACF was quite limited. The adsorption equilibrium was achieved after $12 \mathrm{~min}$. By contrast, when PMS was introduced, about $47 \%$ of the azophloxine was removed by the Fe-Alg/PMS system. This indicated that PMS can significantly improve the removal of dyes because of its activation by Fe-Alg to generate $\mathrm{SO}_{4}{ }^{\bullet-}$ efficiently. Surprisingly, when the FeAlg-ACF/PMS system was exposed to visible radiation, almost all the azophloxine was rapidly removed from the solution within $24 \mathrm{~min}$. Correspondingly, the characteristic absorption peak of azophloxine at $531 \mathrm{~nm}$ gradually decreased with time and totally disappeared after $24 \mathrm{~min}$ (Figure 2C). This result suggested that azophloxine was degraded rapidly by the FeAlg-ACF/PMS system under visible light irradiation, testified to by the decreasing total organic carbon content from $1.82 \mathrm{mg} / \mathrm{L}$ to $79 \mu \mathrm{g} / \mathrm{L}$. In addition, the nitrate $\left(\mathrm{NO}_{3}{ }^{-}\right)$ concentration increased from $0.3 \mathrm{mg} / \mathrm{L}$ before catalytic degradation to $8.6 \mathrm{mg} / \mathrm{L}$ after $24 \mathrm{~min}$ of treatment. According to the molecular structure of azophloxine, complete degradation of this dye with an initial concentration of $50 \mu \mathrm{mol} / \mathrm{L}$ would generate a nitrate content of $8.6 \mathrm{mg} / \mathrm{L}$ in the resulting solution. Consequently, about $93.5 \%$ of the azophloxine molecules were completely degraded into inorganic compounds after treatment with the FeAlg-ACF/PMS system, which paves the way for developing high-efficiency processes to be subsequently used in environmental catalysis.

(A)

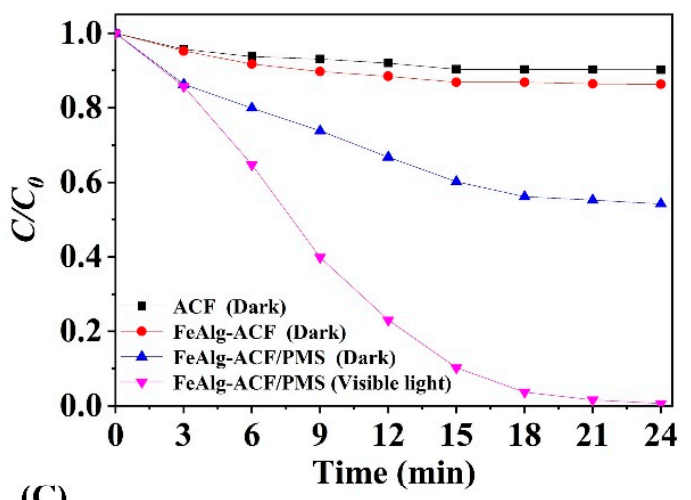

(C)

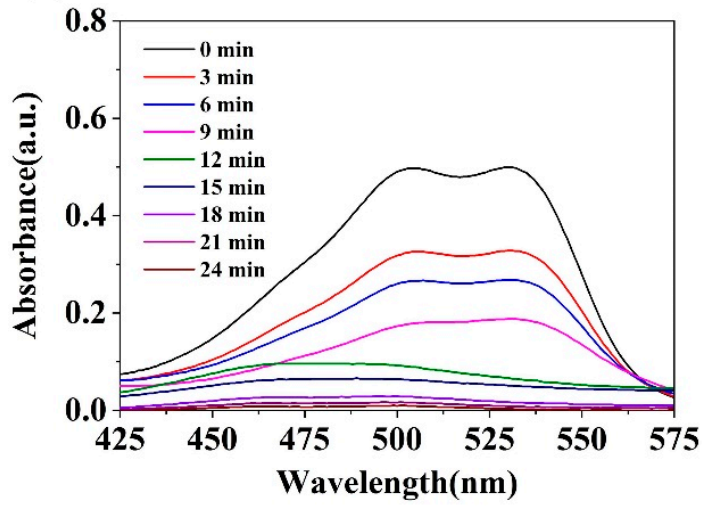

(B)

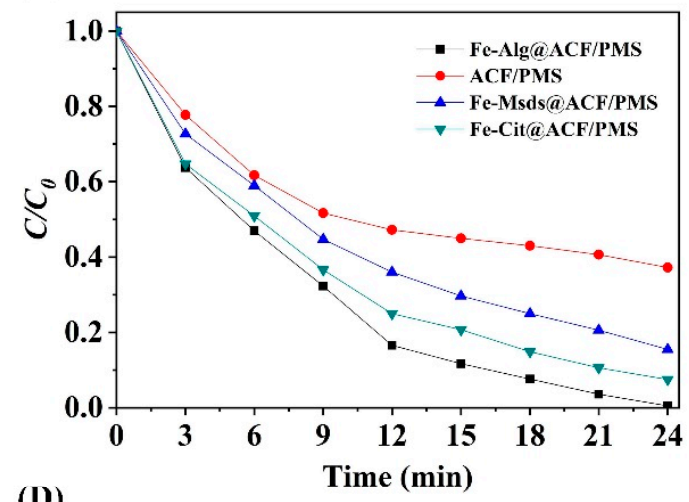

(D)

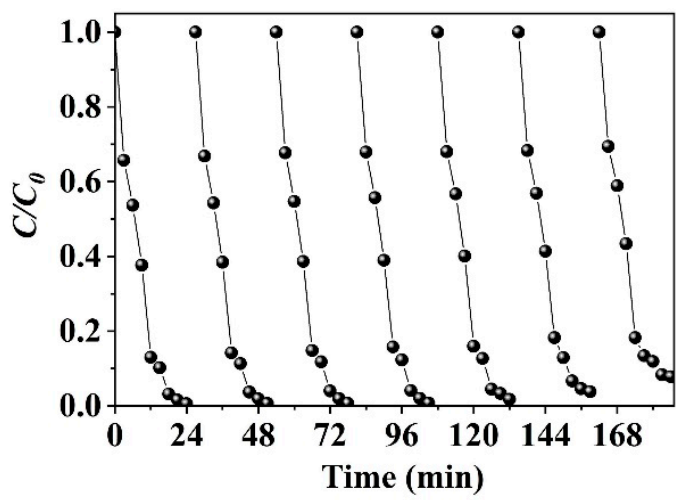

Figure 2. (A) Time-dependent profiles of azophloxine decolorization with and without light irradiation; (B) Decolorization of azophloxine by different systems as a function of time; (C) UV-vis spectra of azophloxine solutions after removal by the FeAlg-ACF/peroxymonosulfate (PMS) system; (D) Azophloxine removal by FeAlg-ACF/PMS after a certain number of cycles. Reaction conditions: $[$ FeAlg-ACF $]=2 \mathrm{~g} / \mathrm{L},[\mathrm{PMS}]=5 \mathrm{mmol} / \mathrm{L}$, [azophloxine $]=50 \mu \mathrm{mol} / \mathrm{L}$, initial $\mathrm{pH}=4.0, \mathrm{~T}=25^{\circ} \mathrm{C}$. 
The effects of different systems on azophloxine removal are compared in Figure 2B. Comparative experiments with ferric alginate (Fe-Alg), ferric citrate (Fe-Cit), and ferric oxalate (Fe-Msds) using the same carrier and oxidant were tested. The results indicated that the proposed catalytic oxidation system can remove $100 \%$ of azophloxine within $24 \mathrm{~min}$, while under the same system, the removal rates were only $92 \%$ and $84 \%$ when Fe-Alg was replaced with Fe-Cit and Fe-Msds, respectively. This is related to the photosensitivity of Fe-Alg and its unique complexation structure. When ACF reacted with the oxidant PMS alone, the removal rate was $60 \%$ after $24 \mathrm{~min}$. This phenomenon is attributed to the fact that ACF is a porous carbon material which can adsorb $8 \%$ azophloxine. On the other hand, ACF will continuously provide PFRs as electronic storage to participate in the LMCT process, and under light irradiation, PMS is activated by electron transfer to produce small amounts of $\mathrm{SO}_{4}{ }^{\bullet-}$ and $\bullet \mathrm{OH}$ to degrade dye.

Our prepared FeAlg-ACF/PMS system could sustain several cycles. As shown in Figure 2D, the azophloxine removal efficiency after 24 min remained almost constant after seven cycles, decreasing only slightly from $100 \%$ to $93 \%$. This is ascribed to the high structural stability, repeatability, and recycling performance of the FeAlg-ACF photocatalyst. Meanwhile, our chosen oxidant PMS is stable during dye treatment, and the treatment process is in line with safety and environmental protection requirements. Furthermore, we also assessed the removal efficiency of our catalytic system for acid orange 7 and methylene blue. The achieved removal ratios of acid orange 7 and methylene blue were $98.0 \%$ and $97.4 \%$ by FeAlg-ACF/PMS under visible light irradiation after 24 min. Our system therefore shows great potential for the removal of reactive dyes, acid dyes, and other typical dyes, and shows promise for applications in dye wastewater treatment and environmental restoration.

\subsection{Effect of Reaction Conditions}

\subsubsection{Effect of PMS Dosage}

PMS produces ROS in the reaction system and provides oxidants for the catalytic degradation of organic pollutants by a catalyst. The removal ratio of azophloxine in our catalytic system varied with the initial PMS concentration, as shown in Figure 3A. After 24 min of treatment, the removal ratio was enhanced from $74 \%$ to $100 \%$ as the PMS dosage was increased from 0 to $5 \mathrm{mmol} / \mathrm{L}$. At the PMS concentration of $5 \mathrm{mmol} / \mathrm{L}$, azophloxine was completely degraded within 9 min when the initial $\mathrm{pH}$ was 4 . The enhanced removal of azophloxine by increasing PMS concentration is attributed to the increased generation of ROS which are conducive to the catalytic reaction. In consideration of environmental protection, economy, and practicability, the initial content of PMS was set as $5 \mathrm{mmol} / \mathrm{L}$ in the following experiments. Besides this, we calculated the utilization efficiency of PMS using the oxidant consumption index $(X)$ : the number of azophloxine removed per mole number of oxidant consumed. A lower $X$ value indicates a higher utilization efficiency of oxidant [51-53]. We calculated that our catalytic system $(X=31.4)$ showed excellent PMS utilization compared with the Fe-Alg/PMS system $(X=43.7)$ and the FeAlg-ACF/PMS system $(X=57.1)$ without visible light radiation. 
(A)

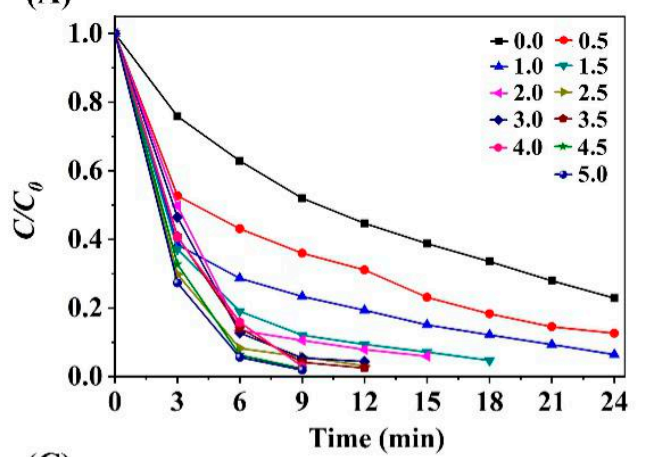

(C)

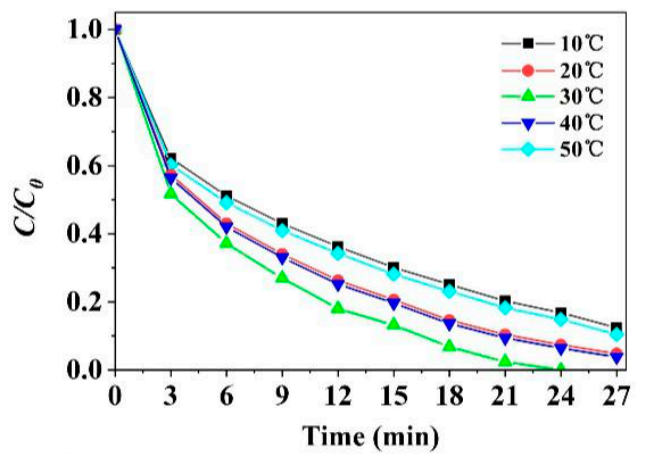

(E)

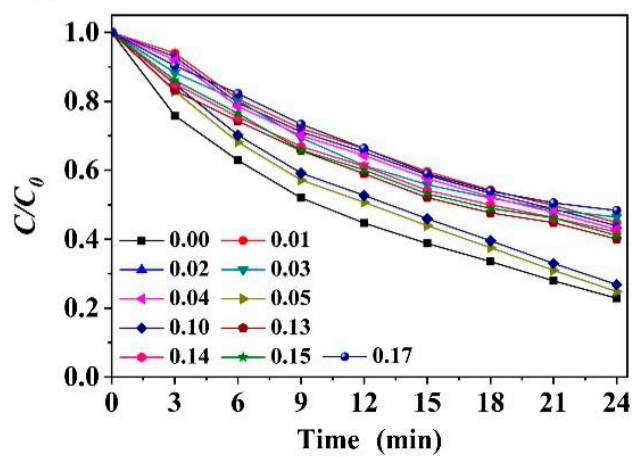

(B)

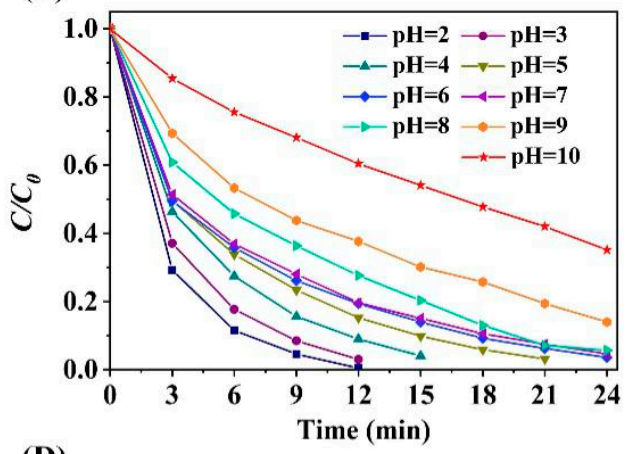

(D)

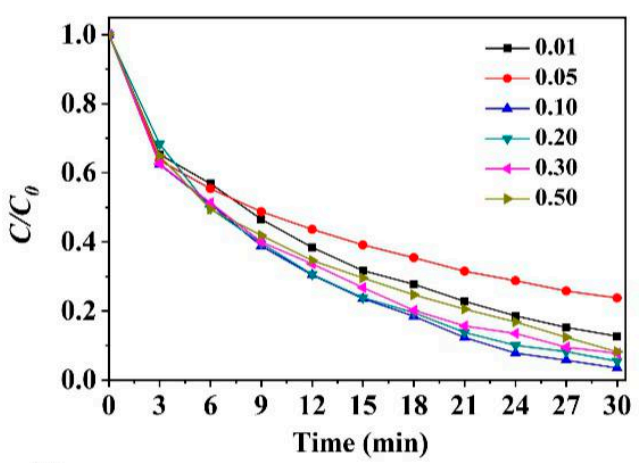

(F)

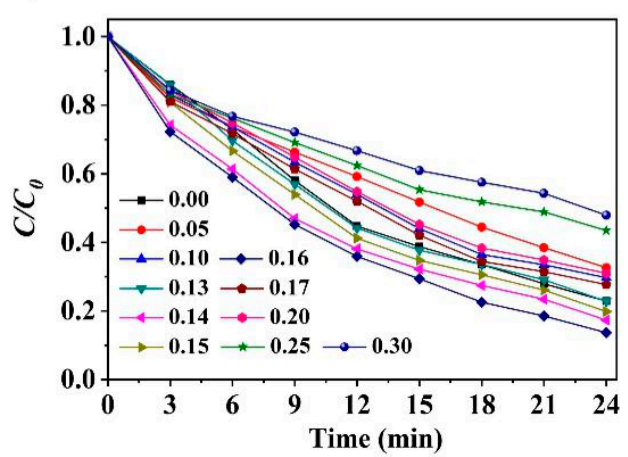

Figure 3. Time-dependent profiles of azophloxine removal under in different conditions: (A) Effect of PMS dosage. Reaction conditions: $\mathrm{T}=25^{\circ} \mathrm{C}, \mathrm{pH}=4 ;(\mathbf{B})$ Effect of initial $\mathrm{pH}$. Reaction conditions: $[\mathrm{PMS}]=5 \mathrm{mmol} / \mathrm{L}, \mathrm{T}=25^{\circ} \mathrm{C}$; (C) Effect of reaction temperature; (D) Effect of initial NaCl concentration; Concentration unit: $\mathrm{mmol} / \mathrm{L} ;$ (E) Effect of initial $\mathrm{Na}_{2} \mathrm{CO}_{3}$ concentration. Concentration unit: $\mathrm{mmol} / \mathrm{L}$; (F) Effect of initial $\mathrm{NaHCO}_{3}$ concentration. Concentration unit: mmol/L; (C-F) Reaction conditions: $[P M S]=5 \mathrm{mmol} / \mathrm{L}, \mathrm{T}=25^{\circ} \mathrm{C}, \mathrm{pH}=6$. Other chemical reagents used: [FeAlg-ACF] $=2 \mathrm{~g} / \mathrm{L}$, [azophloxine] $=50 \mu \mathrm{mol} / \mathrm{L}$.

\subsubsection{Effect of Initial $\mathrm{pH}$ Value}

The influence of the initial $\mathrm{pH}$ value on azophloxine removal is illustrated in Figure 3B. More than $95 \%$ of azophloxine was removed by the FeAlg-ACF/PMS system at $\mathrm{pH}$ values of 2.0-8.0 within $24 \mathrm{~min}$ when other parameters were kept constant. $\mathrm{S}_{2} \mathrm{O}_{8}{ }^{2-}$ ions that are produced by PMS after activation can react with water or $\mathrm{OH}^{-}$to produce $\bullet \mathrm{OH}$. The $\mathrm{SO}_{4}{ }^{\bullet-}$ and $\bullet \mathrm{OH}$ mainly come from PMS photolysis, $\mathrm{SO}_{4}{ }^{\bullet-}$ decay, and transformation of $\mathrm{SO}_{4}{ }^{\bullet-}$ to $\bullet \mathrm{OH}$. When the $\mathrm{pH}$ is greater than 7 , the ROS in the system are dominated by $\bullet \mathrm{OH}$. When the $\mathrm{pH}$ value is $7, \mathrm{SO}_{4}{ }^{\bullet-}$ is equally as involved in oxidation as $\bullet \mathrm{OH}$ (Equations (8) and (9)).

$$
\mathrm{SO}_{4}^{\bullet-}+\mathrm{H}_{2} \mathrm{O} \rightarrow \mathrm{SO}_{4}{ }^{2-}+\bullet \mathrm{OH}+\mathrm{H}^{+}
$$




$$
\mathrm{SO}_{4}{ }^{--}+\mathrm{OH}^{-} \rightarrow \mathrm{SO}_{4}{ }^{2-}+\bullet \mathrm{OH}
$$

Compared with the typical Fenton system, our system shows excellent degradation performance under weak alkaline conditions. This is because as the $\mathrm{pH}$ value increases, the carboxyl dissociation on alginate is in a state of negative charge, and the pores number of the gel structure increase under the action of electrostatic repulsion, so the ability to absorb dye molecules is enhanced. The removal ratio of azophloxine generally decreases with increasing $\mathrm{pH}$ value (Figure $3 \mathrm{~B}$ ). When the initial $\mathrm{pH}$ value was 2.0 , the time required to completely remove azophloxine was only $12 \mathrm{~min}$, which was quite superior when compared with other photocatalytic Fenton systems [54,55]. At an initial pH value of 10.0, however, the azophloxine removal ratio significantly declined to only $65 \%$ after $24 \mathrm{~min}$, but there was still a downward trend. This result also indicated that our FeAlg-ACF/PMS could effectively remove azophloxine in a wide $\mathrm{pH}$ range of $2-10$. By contrast, traditional homogeneous or heterogeneous Fenton systems only work in narrow pH ranges (usually 2-4) [56,57].

\subsubsection{Effect of Treatment Temperature}

Temperature is an important factor affecting the process of activating PMS to degrade organic matter. Increasing the temperature can not only promote molecular thermal movement which improves the reaction rate of wastewater treatment but can also make the reaction system more easily overcome the reaction activation energy. As shown in Figure 3C, when the reaction temperature was lower than $30^{\circ} \mathrm{C}$, the removal of azophloxine increased with increasing temperature. When the temperature was higher than $30^{\circ} \mathrm{C}$, on the contrary, the photocatalytic degradation of azophloxine generally declined with increasing temperature. When the reaction temperature reached $50{ }^{\circ} \mathrm{C}$, the azophloxine removal ratio was $90 \%$ after processing for $27 \mathrm{~min}$. Because room temperature was close to the optimal reaction temperature $\left(30^{\circ} \mathrm{C}\right)$, the reaction temperature was set at $25^{\circ} \mathrm{C}$ in the following experiments to facilitate the operation of experiments.

\subsubsection{Impact of Ion Strength}

Chloride can promote the transfer of dye from the aqueous phase to the fibrous phase and is thus widely used in the printing and dyeing industry. Besides this, there is a mass of chloride, carbanion, and bicarbonate ions in the seawater system [58]. Therefore, it is necessary to study the effect of chloride, carbanion, and bicarbonate ions on the oxidation activity of the catalytic system.

Figure 3D shows the change in the azophloxine removal rate in our catalytic system under different concentrations of $\mathrm{NaCl}$. As shown in Figure 3D, when the $\mathrm{NaCl}$ concentration increased from 0 to $0.05 \mathrm{mmol} / \mathrm{L}$, the removal rate of azophloxine in our catalytic system decreased, which could be attributed to the scavenging effect of $\bullet \mathrm{OH}$ in $\mathrm{NaCl}$. In our catalytic system, when the $\mathrm{NaCl}$ concentration increased from $0.05 \mathrm{mmol} / \mathrm{L}$ to $0.1 \mathrm{mmol} / \mathrm{L}$, the azophloxine removal rate increased. When the chloride concentration was $0.1 \mathrm{mmol} / \mathrm{L}$, the azophloxine removal rate was the highest, reaching $98 \%$ removal rate within $30 \mathrm{~min}$. Chloride ions promoted pollutant removal. However, when the $\mathrm{NaCl}$ concentration exceeded $0.1 \mathrm{mmol} / \mathrm{L}$, with further increase of the $\mathrm{NaCl}$ concentration, the azophloxine removal rate decreased; this showed that a high concentration of chloride inhibited azophloxine degradation.

The effect of widespread carbanion $\left(\mathrm{CO}_{3}{ }^{2-}\right)$ ions in seawater on azophloxine degradation is illustrated in Figure 3E: when the concentration of $\mathrm{CO}_{3}{ }^{2-}$ increased, the removal rate of azophloxine became faster, which demonstrated that the introduction of $\mathrm{CO}_{3}{ }^{2-}$ promoted the removal of azophloxine. The introduction of $\mathrm{HCO}_{3}{ }^{-}$had a slight inhibitory effect on the removal of azophloxine, and with increasing $\mathrm{HCO}_{3}{ }^{-}$concentration, an overall effect appeared of first promoting and then inhibiting, as presented in Figure 3F. Therefore, we speculate that a low concentration of $\mathrm{HCO}_{3}{ }^{-}$is involved in the pathway to promote the generation of $\bullet \mathrm{OH}$ and $\mathrm{SO}_{4}{ }^{\bullet-}$, thus promoting the removal of azophloxine, while an excessive concentration of $\mathrm{HCO}_{3}{ }^{-}$could capture $\mathrm{ROS}$ generated by the reaction to restrain the removal of azophloxine. 


\subsection{Comparison between the FeCit-ACFs/PMS/Visible Light and FeAlg-ACFs/PMS/Visible Light Systems}

The Fe(III)-carboxylate complex, FeCit-ACFs/PMS/visible light, was tested for degradation under the same conditions. This system is able to degrade azophloxine within $33 \mathrm{~min}$, while our catalytic oxidation system, FeAlg-ACFs/PMS/visible light, in the same conditions can degrade azophloxine within $21 \mathrm{~min}$, and the reusability is better.

To further assess the difference in catalytic oxidation activity of these two systems, we adopted a general pseudo-first-order kinetic model $\left(\ln \left(C_{t} / C_{0}\right) / k_{o b s} t\right)$. As shown in Figure 4 , the $k_{o b s}$ for FeAlg-ACFs/PMS/visible light was calculated to be $0.19694 \mathrm{~min}^{-1}$, which was almost twofold higher than that for FeCit-ACFs/PMS/visible light $\left(0.1098 \mathrm{~min}^{-1}\right)$.

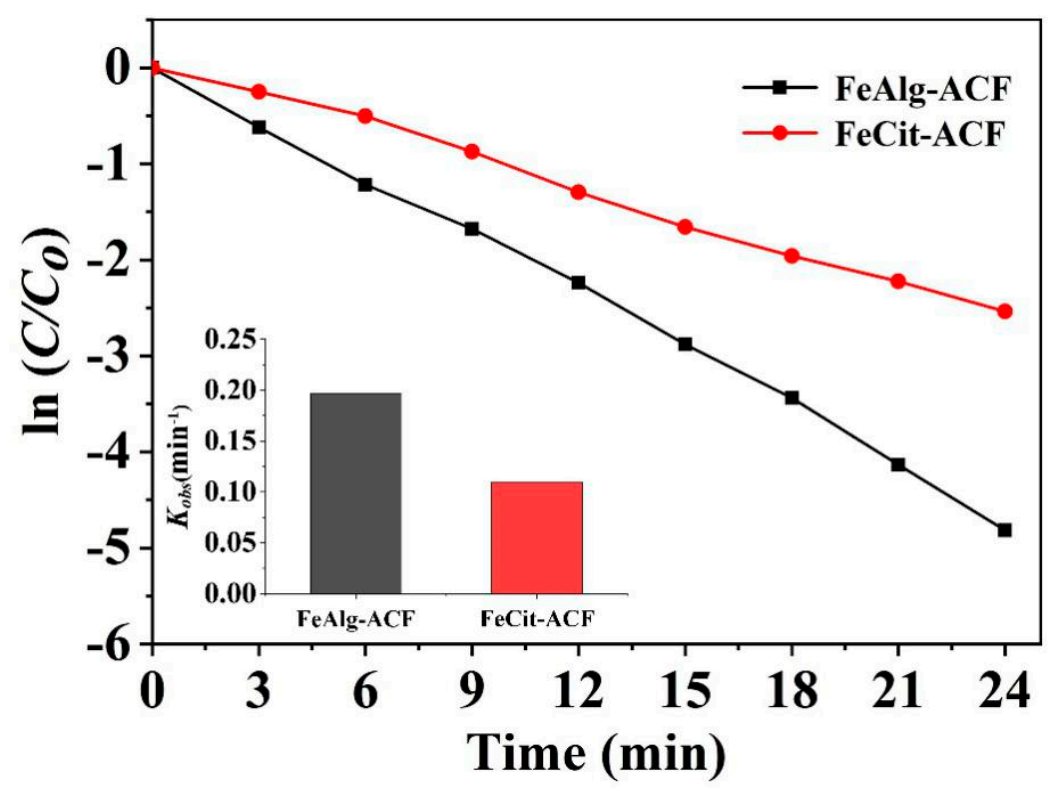

Figure 4. Time profiles of azophloxine decolorization in FeAlg-ACFs/PMS/visible light and FeCit-ACFs/PMS/visible light; the inset shows the $\mathrm{k}_{\mathrm{obs}}$ values of the corresponding systems. Reaction conditions: [PMS] $=5 \mathrm{mmol} / \mathrm{L}, \mathrm{T}=25^{\circ} \mathrm{C}, \mathrm{pH}=6$. Other chemical reagents used: [FeAlg-ACF] $=2 \mathrm{~g} / \mathrm{L},[$ FeCit-ACF] $=2 \mathrm{~g} / \mathrm{L}$, [azophloxine $]=50 \mu \mathrm{mol} / \mathrm{L}$.

\subsection{Reaction Kinetics of Catalytic Oxidation by the FeAlg-ACF/PMS System}

Two models-pseudo-first-order and pseudo-second-order-were used to investigate the degradation kinetics of azophloxine degradation by the FeAlg-ACFs/PMS system. The pseudo-first-order model was first described by Lagergren (1898) and can be generally expressed as follows:

$$
\log \left(\mathrm{q}_{\mathrm{e}}-\mathrm{q}_{\mathrm{t}}\right)=\log \mathrm{q}_{\mathrm{e}}-\mathrm{k}_{1} \mathrm{t} / 2.303
$$

where $q_{t}$ is the amount of azophloxine removed at time $t(\mathrm{~min})$ and $k_{1}$ is the equilibrium rate constant $\left(\min ^{-1}\right)$. The values of $\log \left(\mathrm{q}_{\mathrm{e}}-\mathrm{q}_{\mathrm{t}}\right)$ are linearly related with $\mathrm{t}$, while $\mathrm{k}_{1}$ and $\mathrm{q}_{\mathrm{e}}$ can be determined from the slope and intercept of the plot of $\log \left(\mathrm{q}_{\mathrm{e}}-\mathrm{q}_{\mathrm{t}}\right)$ versus $\mathrm{t}$, respectively.

A pseudo-second-order model, known as Ho's pseudo-second-order model, was also applied to analyze the degradation kinetics of azophloxine by using the equation below:

$$
\mathrm{t} / \mathrm{q}_{\mathrm{t}}=1 /\left(\mathrm{k}_{2} \mathrm{qe}^{2}\right)+\mathrm{t} / \mathrm{q}_{\mathrm{e}}
$$

where $k_{2}$ is the rate constant of second-order degradation $\left(\mathrm{g} \mathrm{mg}^{-1} \mathrm{~min}^{-1}\right)$ and $\mathrm{k}_{2} \mathrm{q}^{2} \mathrm{e}_{\mathrm{e}}$ is the initial degradation rate constant $(\mathrm{h})$. The plot of $\mathrm{t} / \mathrm{q}_{\mathrm{t}}$ versus $\mathrm{t}$ should exhibit a linear relationship, and $\mathrm{q}_{\mathrm{e}}$ and $\mathrm{k}_{2}$ can then be determined from the slope and intercept of the plot, respectively. 
These models were tested against the degradation of azophloxine and the best model was selected depending on the linear regression correlation coefficient, $\mathrm{r}^{2}$. Table 1 shows the parameters of these degradation kinetic models. The pseudo-first-order kinetic model was $-\ln \left(C_{t} / C_{0}\right)=-0.19694 t-$ 0.04125 , and the $R^{2}$ value was 0.99524 , while the pseudo-second-order kinetic model was $1 / C_{t}=$ $-0.09478 \mathrm{t}-21.84025$, and the $\mathrm{R}^{2}$ value was 0.98076 . We can conclude that the pseudo-second-order model is not suitable to model the degradation of azophloxine by the FeAlg-ACFs/PMS system because of its relatively low $\mathrm{r}^{2}$ value. The experimental data fit well with the pseudo-first-order model with $\mathrm{r}^{2}>0.99$.

Table 1. Kinetic constants of azophloxine degradation by the FeAlg-ACFs/PMS/visible light system.

\begin{tabular}{ccccc}
\hline \multirow{2}{*}{ Dye } & $\begin{array}{c}\text { Dynamic } \\
\text { Equation Series }\end{array}$ & $\begin{array}{c}\text { The Fitted } \\
\text { Reaction Rate } \\
\text { Equation }\end{array}$ & $\mathbf{k}_{\text {obs }}$ & Adj. R-Square \\
\hline \multirow{3}{*}{ azophloxine } & $\begin{array}{c}\text { pseudo-first-order } \\
\text { kinetic model }\end{array}$ & $\begin{array}{c}-\ln \left(\mathrm{C}_{\mathrm{t}} / \mathrm{C}_{0}\right)= \\
-0.19694 \mathrm{t}-0.04125\end{array}$ & 0.19694 & 0.99524 \\
\cline { 2 - 5 } & $\begin{array}{c}\text { pseudo-second-order } \\
\text { kinetic model }\end{array}$ & $\begin{array}{c}1 / \mathrm{C}_{\mathrm{t}}=-0.09478 \mathrm{t}- \\
21.84025\end{array}$ & 0.09478 & 0.98076 \\
\hline
\end{tabular}

To better analyze the degradation rate of azophloxine, in-depth theoretical study of the degradation of the target pollutant azophloxine by the reaction system was conducted. Pseudo-first-order dynamics fitting and pseudo-second-order dynamics fitting were performed on the initial $24 \mathrm{~min}$ of azophloxine degradation. The fitting results are presented in Figure 5, and the fitting kinetic constants are presented in Table 1.

(A)

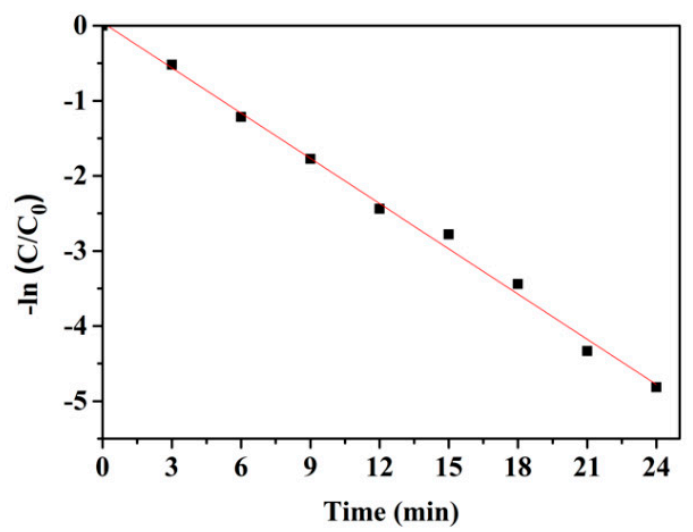

(B)

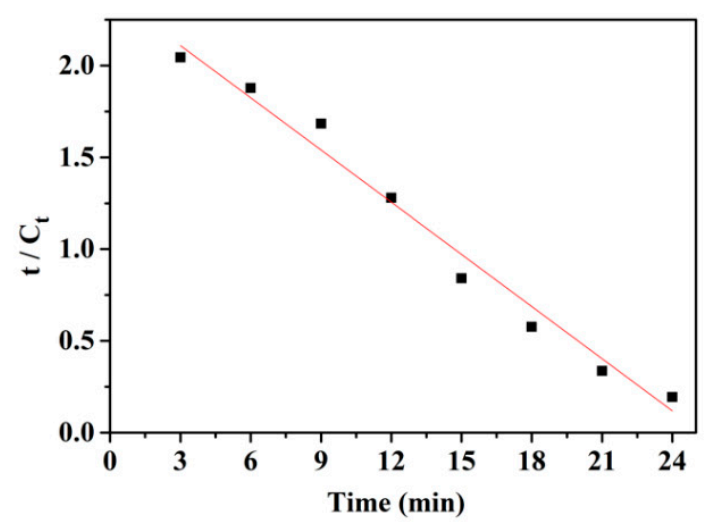

Figure 5. (A) Pseudo-first-order kinetic fitting and (B) pseudo-second-order kinetics fitting of azophloxine degradation. Reaction conditions: $[\mathrm{PMS}]=5 \mathrm{mmol} / \mathrm{L}, \mathrm{T}=25^{\circ} \mathrm{C}, \mathrm{pH}=6$. Other chemical reagents used: $[\mathrm{FeAlg}-\mathrm{ACF}]=2 \mathrm{~g} / \mathrm{L}$, [azophloxine $]=50 \mu \mathrm{mol} / \mathrm{L}$.

According to the azophloxine dye degradation conditions and the dynamic test data of the kinetics of primary and secondary fitting, it can be seen that for the FeAlg-ACFs/PMS system's oxidative degradation of azophloxine, the correlation coefficient of the first-order kinetics reaction is greater than the secondary dynamic correlation coefficient, showing that the dye degradation process is in line with a first-order kinetics reaction process. The degradation rate constant $\left(\mathrm{k}_{\mathrm{obs}}\right)$ of azophloxine was found to be 0.19694 .

Applying the principle of chemical kinetics to the field of the environment, not only can the mechanism of pollutant degradation be studied, but also the influencing factors of pollutant degradation can be determined and stabilization measures can be developed. 


\subsection{Mechanism of Catalytic Oxidation by the FeAlg-ACF/PMS System}

The oxidation of organic pollutants was mainly contributed by ROS generated by PMS oxidation. In this study, we used t-butanol (TBA) and methanol (MA) to study the variation of ROS in the reaction system because MA is highly reactive with $\mathrm{SO}^{\bullet-}$ and $\bullet \mathrm{OH}$, while TBA only shows high reactivity with $\bullet \mathrm{OH}[59]$.

As shown in Figure 6A, when 0.5 M TBA was added into our catalytic degradation system, the overall removal ratio of azophloxine dropped sharply from $100 \%$ to $42.3 \%$. Therefore, $\bullet \mathrm{OH}$ plays an important role in the photocatalytic oxidation reaction. Furthermore, when $0.5 \mathrm{M}$ MA was added into the catalytic system, the removal rate declined to $26.8 \%$. This suggests that the inhibition of azophloxine removal by MA was more significant than that by TBA because MA is highly reactive with both $\bullet \mathrm{OH}$ and $\mathrm{SO}^{\bullet}{ }^{-}$. Considering the possible influence of competitive adsorption, we further supplemented the free radical capture experiment under dark conditions, as shown in Figure 6B. In the figure, it can be observed that the overall effect under dark reaction conditions was worse than that under light, and the degradation rates with MA and TBA were further reduced, proving that both $\bullet \mathrm{OH}$ and $\mathrm{SO} 4^{\bullet-}$ are essential to the catalytic degradation of azophloxine. The reaction process of PMS activation is shown in Equations (12)-(15).

(A)

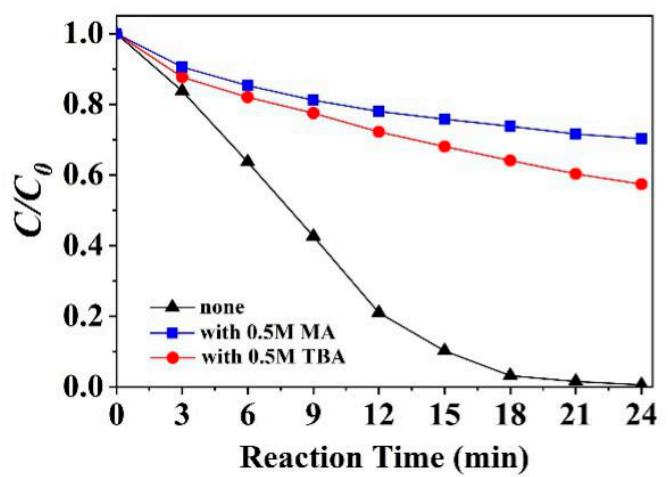

(B)

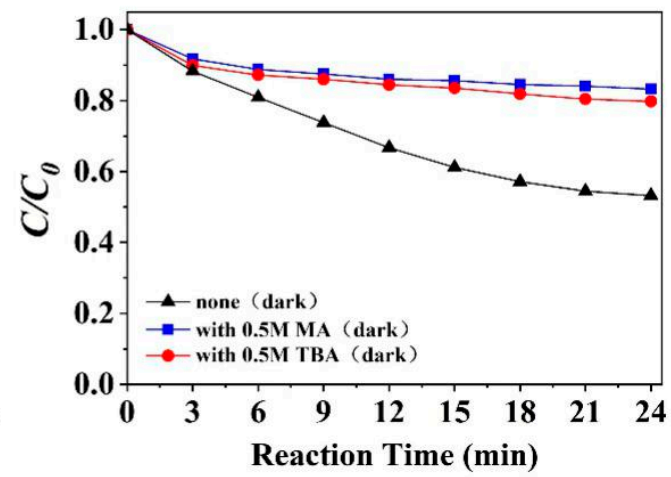

Figure 6. Effects of t-butanol (TBA) and methanol (MA) on azophloxine removal by the FeAlg-ACF/PMS system: (A) with light irradiation; (B) without light irradiation. Reaction conditions: $[\mathrm{FeAlg}-\mathrm{ACF}]=$ $2 \mathrm{~g} / \mathrm{L},[\mathrm{PMS}]=5 \mathrm{mmol} / \mathrm{L}$, [azophloxine] $=50 \mu \mathrm{mol} / \mathrm{L}$, initial $\mathrm{pH}=6.0, \mathrm{~T}=25^{\circ} \mathrm{C}$.

$$
\begin{gathered}
\mathrm{M}^{2+}+\mathrm{HSO}_{5}{ }^{-} \rightarrow \mathrm{M}^{3+}+\mathrm{SO}_{4}{ }^{\bullet-}+\mathrm{OH}^{-} \\
\mathrm{SO}_{4}{ }^{\bullet-}+\mathrm{OH}^{-} \rightarrow \mathrm{SO}_{4}{ }^{2-}+\bullet \mathrm{OH} \\
\mathrm{M}^{3+}+\mathrm{HSO}_{5}{ }^{-} \rightarrow \mathrm{M}^{2+}+\mathrm{SO}_{5}{ }^{\bullet-}+\mathrm{H}_{2} \mathrm{O} \\
\mathrm{SO}_{5}{ }^{--}+\mathrm{O}_{2}{ }^{-} \rightarrow \mathrm{SO}_{4}{ }^{--}+\mathrm{O}_{2}
\end{gathered}
$$

To further understand the mechanism of ACF in the catalytic degradation system, we performed $\mathrm{X}$-ray photoelectron spectroscopy analysis and determined the structural changes in FeAlg-ACF after the reaction. The peaks at $531.6 \mathrm{eV}$ and $533.1 \mathrm{eV}$ correspond to the oxygen atoms in the carbonyl group $(\mathrm{C}=\mathrm{O})$ and hydroxyl group $(-\mathrm{O}-\mathrm{H})$, respectively. As shown in Figure 7 , the peak strength of oxygen in the $\mathrm{C}-\mathrm{O}-\mathrm{H}$ group decreased after the catalytic degradation of azophloxine. By contrast, the peak strength of oxygen proportionally increased in the $\mathrm{C}=\mathrm{O}$ bond. This suggests that $\mathrm{C}-\mathrm{O}-\mathrm{H}$ groups were transformed into $\mathrm{C}=\mathrm{O}$ during azophloxine removal. This change confirmed that PFRs in 
ACF supplied electrons to $\mathrm{Fe}(\mathrm{III})$-Alg, and electron transfer accelerated the $\mathrm{Fe}$ (III)-to-Fe(II) reduction process, which was the key step in accelerating the Fenton-like reaction.
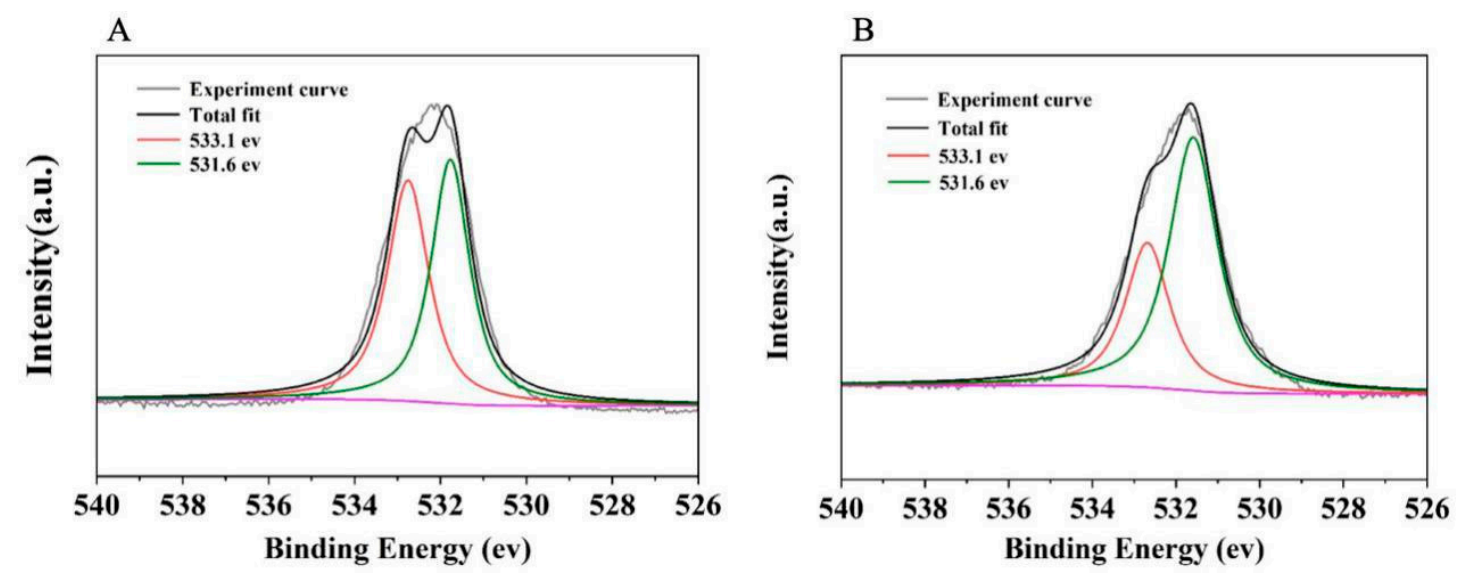

Figure 7. XPS spectra of $\mathrm{O} 1 \mathrm{~s}$ in FeAlg-ACF before (A) and after (B) its utilization in the FeAlg-ACF/PMS/visible light system. Reaction conditions: $[\mathrm{FeAlg}-\mathrm{ACF}]=2 \mathrm{~g} / \mathrm{L},[\mathrm{PMS}]=5 \mathrm{mmol} / \mathrm{L}$, [azophloxine] $=50 \mu \mathrm{mol} / \mathrm{L}$, initial $\mathrm{pH}=6.0, \mathrm{~T}=25^{\circ} \mathrm{C}$.

In conclusion, we propose a mechanism to explain azophloxine removal by the FeAlg-ACF/PMS system. First, the PFRs in ACF, as electronic storage, provide electrons to the Fe-Alg complex, which accelerates the LMCT process. At the same time, due to the high photosensitivity of the Fe-Alg complex, visible light radiation further enhances the LMCT process. Therefore, as a distinctive heterogeneous photocatalyst, FeAlg-ACF can effectively activate PMS to produce $\bullet \mathrm{OH}$ and $\mathrm{SO}_{4}{ }^{\bullet-}$ to degrade organic dyes rapidly under visible light.

\section{Experimental}

\subsection{Materials}

Activated carbon fiber (ACF) was purchased from Jiangsu Sutong Carbon Fiber Co., Ltd. (Nantong, China). $\mathrm{FeCl}_{3} \cdot 6 \mathrm{H}_{2} \mathrm{O}$ of analytical purity and sodium alginate $\left(\mathrm{C}_{6} \mathrm{H}_{7} \mathrm{NaO}_{6}\right)_{n}$ of chemical purity were obtained from Sinopharm Chemical Reagent Co., Ltd. (Shanghai, China). Peroxymonosulfate (PMS) of analytical purity was provided by Aladdin biological technology Co., Ltd. (Shanghai, China). Azophloxine (analytical purity) was purchased from Macklin Biochemical Co., Ltd. (Shanghai, China). Rhodamine B (analytical purity), acid orange 7 (analytical purity), and methylene blue (analytical purity) were supplied by Sinopharm Chemical Reagent Co., Ltd. We used ultrapure water throughout the experiment.

\subsection{Sample Preparation}

The preparation scheme of the FeAlg-ACF catalyst is shown in Figure 8. A certain amount of ACF (10 g) was soaked in $3 \mathrm{~mol} / \mathrm{L}$ nitric acid solution, then heated in a water bath at $30^{\circ} \mathrm{C}$ for $12 \mathrm{~h}$. The acidified ACF was repeatedly rinsed by ultrapure water and was then dried in a vacuum drying oven (Shanghai Yiheng Scientific Instrument Co., Ltd., Shanghai, China, DZF-6020) at $30^{\circ} \mathrm{C}$. Ferric chloride and sodium alginate were combined to form a suspension of ferric alginate at a 1:1 mass ratio via the ultrasonic stirring method. The acidified ACF was then immersed in the ferric alginate solution at $25^{\circ} \mathrm{C}$ for $24 \mathrm{~h}$. After rinsing by ultrapure water and drying at $30^{\circ} \mathrm{C}$, the novel heterogeneous catalyst FeAlg-ACF was obtained. 


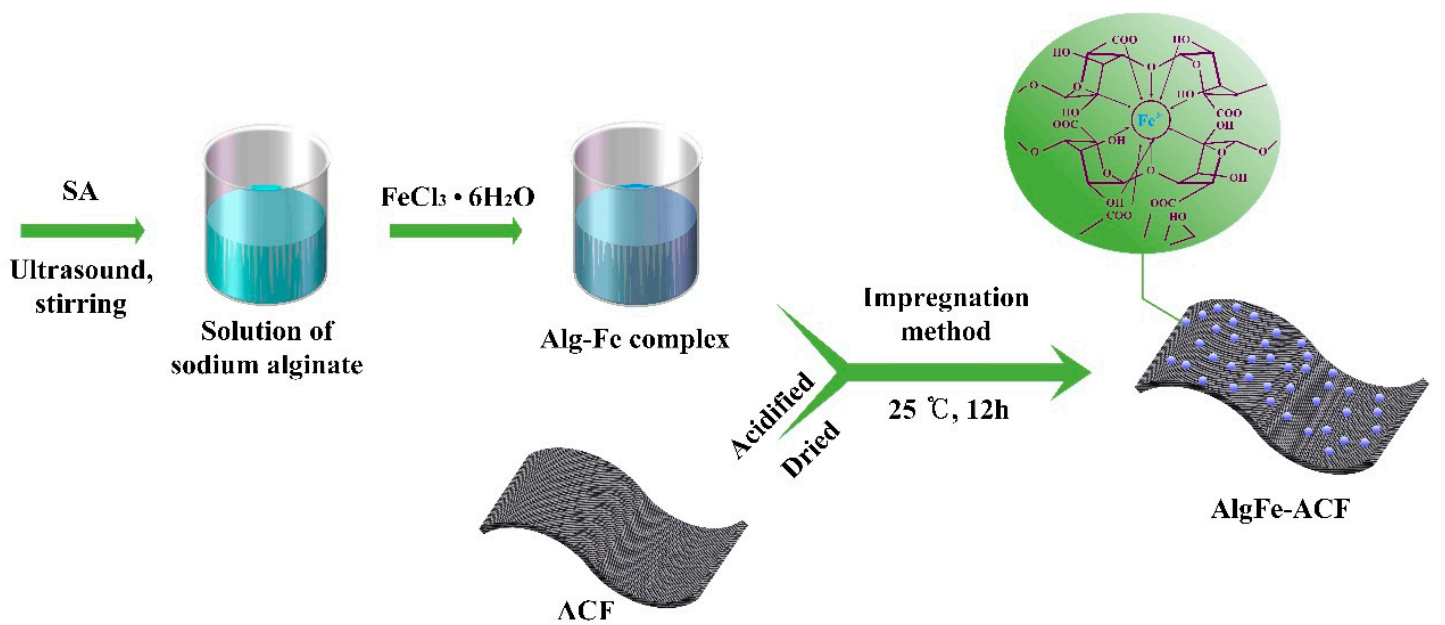

Figure 8. Schematic diagram of the preparation process of the heterogeneous photocatalysis FeAlg-ACF.

\subsection{Dye Removal by FeAlg-ACF}

The photocatalytic degradation of azophloxine was conducted in a photochemical reaction apparatus (Shanghai Yuncao, YCYN-GHX-D, Shanghai, China), equipped with a $500 \mathrm{~W}$ mercury lamp which irradiated the dyes at a distance of $10 \mathrm{~cm}$ through an ultraviolet glass cut-off filter $(400 \mathrm{~nm})$. The temperature was kept at $25^{\circ} \mathrm{C}$ throughout the reaction. The reaction system was composed of azophloxine at an initial concentration of $50 \mu \mathrm{mol} / \mathrm{L}, \mathrm{FeAlg}-\mathrm{ACF}$ at a dosage of $2 \mathrm{~g} / \mathrm{L}$, and PMS at an initial content of $5 \mathrm{mmol} / \mathrm{L}$. $\mathrm{NaOH}$ or $\mathrm{HCl}$ solution was used to adjust the initial $\mathrm{pH}$ value of the reaction system. The reaction system was treated in dark for $6 \mathrm{~min}$, followed by photocatalytic degradation with a time interval of $3 \mathrm{~min}$. The absorbance of azophloxine was determined using a UV-visible spectrophotometer (Shimadzu, Kyoto, Japan, UV-2550) at a maximum wavelength of $531 \mathrm{~nm}$. According to the change in the absorption value of the sample before and after the reaction, the removal ratio $(\mathrm{v})$ was calculated according to the absorbance of the solution before and after the treatment, using the following equation:

$$
\mathrm{v}=\mathrm{C}_{\mathrm{t}} / \mathrm{C}_{0} \times 100 \%=\mathrm{A}_{\mathrm{t}} / \mathrm{A}_{0} \times 100 \%
$$

where $C_{0}$ is the initial concentration of azophloxine, $C_{t}$ is the azophloxine concentration after reaction time $t, A_{0}$ is used to show the initial absorbance of azophloxine, and $A_{t}$ is the absorbance of azophloxine after the reaction time [51-53].

\subsection{Characterization}

The surface morphology of the prepared catalyst was observed by scanning electron microscopy (ZEISS Sigma 500/VP Field emission scanning electron microscope). The iron content of the solution after the formation of FeAlg-ACF was determined by PANalytical X-ray fluorescence spectrometry (DY1040). The binding site of O1s was determined by X-ray photoelectron spectroscopy (XPS, Kratos Axis Ultra DLD, Kratos Analytical, Manchester, UK). The binding energy peaks of all XPS spectra were calibrated by using the binding energy peaks of $284.7 \mathrm{eV}$ for principal C1s. The total organic carbon content of the dye solution was measured using a total organic carbon analyzer (Analytik Jena AG, Jena, Germany, model 3100) and the nitrate concentration was detected by ion chromatography (Thermo Fisher Scientific, Waltham, MA, USA, Aquion). The characteristic peaks of the reaction solution were explored by LC 3000 high-performance liquid chromatography (Beijing Tong Heng Innovation Technology Co., Ltd., Beijing, China, LC 3000). 


\section{Conclusions}

In summary, we fabricated a novel heterogeneous catalyst, FeAlg-ACF, via a single-step process, i.e., the impregnation method. Using this catalyst together with PMS and visible light, we constructed a visible-light photocatalytic degradation system to remove azophloxine from aqueous solution. Azophloxine was completely removed after only $24 \mathrm{~min}$ processing by this novel system. In addition, the results indicated that more than $93.5 \%$ of the azophloxine was completely degraded into inorganic compounds; thus, potential secondary contamination by intermediate products during catalytic degradation can be inhibited. Compared to iron alginate gel beads, the dye removal efficiency was improved by the large specific surface area and PFRs provided by the carrier ACF. Moreover, the prepared heterogeneous catalyst FeAlg-ACF exhibits the advantages of reusability, a wide range of $\mathrm{pH}$ applications (2-10), and availability in visible light. With the additional advantage of recycled usage and ion applicability, the proposed FeAlg-ACF/PMS system can potentially be applied in the efficient and environmentally friendly removal of dye from wastewater.

Author Contributions: Conceptualization, D.W.; Data curation, D.W.; Formal analysis, D.W.; Investigation, K.X.; Methodology, K.X.; Software, C.F.; Supervision, Y.Y.; Writing-review \& editing, X.C. All authors have read and agreed to the published version of the manuscript.

Funding: This research received no external funding.

Acknowledgments: The authors would like to thank the Ocean College Experimental Teaching Center of Zhejiang University for SEM characterization, and State Key Laboratory of Silicon Materials of Zhejiang University for XPS characterization. The authors also thank Lu et al. in the Department of Chemistry, Zhejiang University for helpful discussions and assistance in experiments. This research received no external funding.

Conflicts of Interest: We declare no conflict of interest exits in the submission of this manuscript, and manuscript is approved by all authors for publication.

\section{References}

1. Sakaue, S.; Tsubakino, T.; Nishiyama, Y.; Ishii, Y.; Org, J. Oxidation of aromatic amines with hydrogen peroxide catalyzed by cetylpyridinium heteropolyoxometalates. J. Organ. Chem. 1993, 58, 3633-3638. [CrossRef]

2. Dong, C.; Lu, J.; Qiu, B.; Shen, B.; Xing, M.; Zhang, J. Developing stretchable and graphene-oxide-based hydrogel for the removal of organic pollutants and metal ions. Appl. Catal. B Environ. 2018, 222, $146-156$. [CrossRef]

3. Ahmad, M.; Yousaf, M.; Nasir, A.; Bhatti, I.A.; Mahmood, A.; Fang, X.; Jian, X.; Kalantar-Zadeh, K.; Mahmood, N. Porous eleocharis@ MnPE layered hybrid for synergistic adsorption and catalytic biodegradation of toxic Azo dyes from industrial wastewater. Environ. Sci. Technol. 2019, 53, 2161-2170. [CrossRef]

4. Wang, Q.; Huang, L.; Quan, X. Sequential anaerobic and electro-Fenton processes mediated by W and Mo oxides for degradation/mineralization of azo dye methyl orange in photo assisted microbial fuel cells. Appl. Catal. B Environ. 2019, 245, 672-680. [CrossRef]

5. Shukla, P.; Wang, S.; Sun, H.; Ang, H.; Tade, M. Adsorption and heterogeneous advanced oxidation of phenolic contaminants using Fe loaded mesoporous SBA-15 and $\mathrm{H}_{2} \mathrm{O}_{2}$. Chem. Eng. J. 2010, 164, $255-260$. [CrossRef]

6. Luo, W.; Zhu, L.; Wang, N.; Tang, H.; Cao, M.; She, Y. Efficient removal of organic pollutants with magnetic nanoscaled $\mathrm{BiFeO} 3$ as a reusable heterogeneous Fenton-like catalyst. Environ. Sci. Technol. 2020, 44, 1786-1791. [CrossRef]

7. Gao, C.; Chen, S.; Quan, X.; Hong, Y.; Yao, Z. Enhanced Fenton-like catalysis by iron-based metal organic frameworks for degradation of organic pollutants. J. Catal. 2017, 356, 125-132. [CrossRef]

8. Yang, X.; Xu, X.; Xu, J.; Han, Y. Iron oxychloride (FeOCl): An efficient Fenton-like catalyst for producing hydroxyl radicals in degradation of organic contaminants. J. Am. Chem. Soc. 2013, 135, 16058-16061. [CrossRef] [PubMed] 
9. Huang, B.; Qi, C.Y.; Yang, Z.; Guo, Q.; Chen, W.Q.; Zeng, G.M.; Lei, C. Pd/Fe $\mathrm{Fe}_{3} \mathrm{O}_{4}$ nanocatalysts for highly effective and simultaneous removal of humic acids and $\mathrm{Cr}(\mathrm{VI})$ by electro-Fenton with $\mathrm{H}_{2} \mathrm{O}_{2}$ in situ electro-generated on the catalyst surface. J. Catal. 2017, 352, 337-350. [CrossRef]

10. Lachkov, P.T.; Chin, Y.H. Catalytic consequences of reactive oxygen species during $\mathrm{C}_{3} \mathrm{H}_{6}$ oxidation on $\mathrm{Ag}$ clusters. J. Catal. 2018, 366, 127-138. [CrossRef]

11. Wang, J.; Liu, Z.; Cai, R. A new role for $\mathrm{Fe}^{3+}$ in $\mathrm{TiO}_{2}$ hydrosol: Accelerated photodegradation of dyes under visible light. Environ. Sci. Technol. 2008, 42, 5759-5764. [CrossRef]

12. He, W.; Jia, H.; Yang, D.; Xiao, P.; Fan, X.; Zheng, Z.; Kim, H.; Wamer, W.G.; Yin, J. Composition directed generation of reactive oxygen species in irradiated mixed metal sulfides correlated with their photocatalytic activities. ACS Appl. Mater. Inter. 2015, 7, 16440-16449. [CrossRef]

13. Song, K.; Lu, M.; Xu, S.; Chen, C.; Zhan, Y.; Li, D.; Au, C.; Jiang, L.; Tomishige, K. Effect of alloy composition on catalytic performance and coke-resistance property of $\mathrm{Ni}-\mathrm{Cu} / \mathrm{Mg}$ (Al) O catalysts for dry reforming of methane. Appl. Catal. B Environ. 2018, 239, 324-333. [CrossRef]

14. Zhang, B.; Zhang, Y.; Teng, Y. Electrospun magnetic cobalt-carbon nanofiber composites with axis-sheath structure for efficient peroxymonosulfate activation. Appl. Surf. Sci. 2018, 452, 443-450. [CrossRef]

15. Luo, J.; Wang, Y.; Cao, D.; Xiao, K.; Guo, T.; Zhao, X. Enhanced photoelectrocatalytic degradation of 2, 4-dichlorophenol by $\mathrm{TiO}_{2} / \mathrm{Ru}-\mathrm{IrO}_{2}$ bifacial electrode. Chem. Eng. J. 2018, 343, 69-77. [CrossRef]

16. Liu, S.; Zhao, X.; Wang, Y.; Shao, H.; Qiao, M.; Wang, Y.; Zhao, S. Peroxymonosulfate enhanced photoelectrocatalytic degradation of phenol activated by $\mathrm{Co}_{3} \mathrm{O}_{4}$ loaded carbon fiber cathode. J. Catal. 2017, 355, 167-175. [CrossRef]

17. Fan, Z.; Wang, Z.; Shi, J.; Gao, C.; Gao, G.; Wang, B.; Wang, Y.; Chen, X.; He, C.; Niu, C. Charge-redistribution-induced new active sites on $\left(\begin{array}{lll}0 & 0 & 1\end{array}\right)$ facets of $\alpha-\mathrm{Mn}_{2} \mathrm{O}_{3}$ for significantly enhanced selective catalytic reduction of $\mathrm{NO}_{x}$ by $\mathrm{NH}_{3}$. J. Catal. 2019, 370, 30-37. [CrossRef]

18. Luo, L.; Wu, D.; Dai, D.; Yang, Z.; Chen, L.; Liu, Q.; He, J.; Yao, Y. Synergistic effects of persistent free radicals and visible radiation on peroxymonosulfate activation by ferric citrate for the decomposition of organic contaminants. Appl. Catal. B Environ. 2017, 205, 404-411. [CrossRef]

19. Wang, X.N.; Dong, W.B.; Brigante, M.; Mailhot, G. $\mathrm{C}_{60}$ Fullerol Promoted Fe (III)/ $\mathrm{H}_{2} \mathrm{O}_{2}$ Fenton Oxidation: Role of Photosensitive Fe (III)-Fullerol Complex. Appl. Catal. B Environ. 2019, 245, 271-278. [CrossRef]

20. Rastogi, A.; Al-Abed, S.R.; Dionysiou, D.D. Effect of inorganic, synthetic and naturally occurring chelating agents on Fe (II) mediated advanced oxidation of chlorophenols. Water Res. 2009, 43, 684-694. [CrossRef]

21. Ling, L.; Zhang, D.P.; Fang, J.Y.; Fan, C.H.; Shang, C. A novel Fe (II)/citrate/UV/peroxymonosulfate process for micropollutant degradation: Optimization by response surface methodology and effects of water matrices. Chemosphere 2017, 184, 417-428. [CrossRef] [PubMed]

22. Han, D.H.; Wan, J.Q.; Ma, Y.W.; Wang, Y.; Li, Y.; Li, D.Y.; Guan, Z.Y. New insights into the role of organic chelating agents in Fe (II) activated persulfate processes. Chem. Eng. J. 2015, 269, 425-433. [CrossRef]

23. Xu, Z.; Gao, G.; Pan, B.; Zhang, W.; Lv, L. A new combined process for efficient removal of Cu (II) organic complexes from wastewater: Fe (III) displacement/UV degradation/alkaline precipitation. Water Res. 2015, 87, 378-384. [CrossRef] [PubMed]

24. Wang, Z.; Chen, X.; Ji, H.; Ma, W.; Chen, C.; Zhao, J. Photochemical cycling of iron mediated by dicarboxylates: Special effect of malonate. Environ. Sci. Technol. 2010, 44, 263-268. [CrossRef]

25. Pang, H.; Zhang, Q.; Wang, H.; Cai, D.; Ma, Y.; Li, L.; Li, K.; Lu, X.; Chen, H.; Yang, X.; et al. Photochemical Aging of Guaiacol by Fe (III)-Oxalate Complexes in Atmospheric Aqueous Phase. Environ. Sci. Technol. 2019, 53, 127-136. [CrossRef]

26. Chen, J.; Browne, W.R. Photochemistry of iron complexes. Chem. Rev. 2018, 374, 15-35. [CrossRef]

27. Ruales-Lonfat, C.; Barona, J.F.; Sienkiewicz, A.; Vélez, J.; Benítez, L.N.; Pulgarín, C. Bacterial inactivation with iron citrate complex: A new source of dissolved iron in solar photo-Fenton process at near-neutral and alkaline pH. Appl. Catal. B Environ. 2016, 180, 379-390. [CrossRef]

28. Li, L.; Fang, Y.; Vreeker, R.; Appelqvist, I.; Mendes, E. Reexamining the egg-box model in calcium-alginate gels with X-ray diffraction. Biomacromolecules 2007, 8, 464-468. [CrossRef]

29. Dong, Y.; Dong, W.; Cao, Y.; Han, Z.; Ding, Z. Preparation and catalytic activity of Fe alginate gel beads for oxidative degradation of azo dyes under visible light irradiation. Catal. Today 2011, 175, 346-355. [CrossRef] 
30. Fernandez, J.; Dhananjeyan, M.R.; Kiwi, J.; Senuma, Y.; Hilborn, J. Evidence for Fenton photoassisted processes mediated by encapsulated Fe ions at biocompatible $\mathrm{pH}$ values. J. Phys. Chem. B 2000, 104, 5298-5301. [CrossRef]

31. Li, B.; Dong, Y.; Zou, C.; Xu, Y. Iron (III)-alginate fiber complex as a highly effective and stable heterogeneous fenton photocatalyst for mineralization of organic dye. Ind. Eng. Chem. Res. 2014, 53, 4199-4206. [CrossRef]

32. Narayanan, R.P.; Melman, G.; Letourneau, N.J.; Mendelson, N.L.; Melman, A. Photodegradable iron (III) cross-linked alginate gels. Biomacromolecules 2012, 13, 2465-2471. [CrossRef]

33. Titouhi, H.; Belgaied, J.E. Removal of ofloxacin antibiotic using heterogeneous Fenton process over modified alginate beads. J. Environ. Sci. 2016, 45, 84-93. [CrossRef]

34. Iglesias, O.; Gómez, J.; Pazos, M.; Sanromán, M.Á. Electro-fenton oxidation of imidacloprid by fe alginate gel beads. Appl. Catal. B Environ. 2014, 144, 416-424. [CrossRef]

35. Zhang, W.F.; Liu, F.; Sun, Y.G.; Zhang, J.; Hao, Z.P. Simultaneous redox conversion and sequestration of chromate (VI) and arsenite (III) by iron (III)-alginate based photocatalysis. Appl. Catal. B Environ. 2019, 259, 118046. [CrossRef]

36. Tao, X.; Su, J.; Wang, L. A new heterogeneous catalytic system for wastewater treatment: Fe-immobilized polyelectrolyte microshells for accumulation and visible light-assisted photooxidative degradation of dye pollutants. J. Mol. Catal. A Chem. 2008, 280, 186-193. [CrossRef]

37. Lim, S.; Zheng, Y.; Zou, S.; Chen, J.P. Characterization of copper adsorption onto an alginate encapsulated magnetic sorbent by a combined FT-IR, XPS, and mathematical modeling study. Environ. Sci. Technol. 2008, 42, 2551-2556. [CrossRef]

38. Gonzalez-Olmos, R.; Martin, M.J.; Georgi, A.; Kopinke, F.D.; Oller, I.; Malato, S. Fe-zeolites as heterogeneous catalysts in solar fenton-like reactions at neutral ph. Appl. Catal. B Environ. 2012, 125, 51-58. [CrossRef]

39. Ji, H.W.; Song, W.J.; Chen, C.; Yuan, H.; Ma, W.; Zhao, J. Anchored oxygen-donor coordination to iron for photodegradation of organic pollutants. Environ. Sci. Technol. 2007, 41, 5103-5107. [CrossRef] [PubMed]

40. Cheng, M.; Ma, W.H.; Chen, C.; Yao, J.; Zhao, J. Photocatalytic degradation of organic pollutants catalyzed by layered iron(ii) bipyridine complex-clay hybrid under visible irradiation. Appl. Catal. B Environ. 2006, 65, 217-226. [CrossRef]

41. Feng, J.Y.; Hu, X.J.; Yue, P.L. Novel bentonite clay-based Fe-nanocomposite as a heterogeneous catalyst for photo-fenton discoloration and mineralization of orange II. Environ. Sci. Technol. 2004, 38, $269-275$. [CrossRef] [PubMed]

42. Duarte, F.; Maldonado-Hódar, F.J.; Madeira, L.M. Prussian blue onto activated carbon as a catalyst for heterogeneous fenton-like processes. Appl. Catal. B Environ. 2013, 129, 264-272. [CrossRef]

43. Yang, S.; Yang, X.; Shao, X.; Niu, R.; Wang, L. Activated carbon catalyzed persulfate oxidation of Azo dye acid orange 7 at ambient temperature. J. Hazard. Mater. 2011, 186, 659-666. [CrossRef]

44. Hu, L.; Yang, X.; Dang, S. An easily recyclable Co/SBA-15 catalyst: Heterogeneous activation of peroxymonosulfate for the degradation of phenol in water. Appl. Catal. B Environ. 2011, 102, 19-26. [CrossRef]

45. Huang, Y.; Peng, L.; Liu, Y.; Zhao, G.; Chen, J.Y.; Yu, G. Biobased nano porous active carbon fibers for high-performance supercapacitors. ACS Appl. Mater. Inter. 2016, 8, 15205-15215. [CrossRef] [PubMed]

46. Nabais, J.M.V.; Carrott, P.J.M. Chemical characterization of activated carbon fibers and activated carbons. J. Chem. Educ. 2006, 83, 436. [CrossRef]

47. Yao, Y.; Wang, L.; Sun, L.; Zhu, S.; Huang, Z.; Mao, Y.; Lu, W.; Chen, W. Efficient removal of dyes using heterogeneous Fenton catalysts based on activated carbon fibers with enhanced activity. Chem. Eng. Sci. 2013, 101, 424-431. [CrossRef]

48. Zhang, Y.; Tang, Y.; Qiu, Q.; Chen, Y.; Sun, Y.; Wan, P.; Yang, X.J. Electrochemically Enhanced Adsorption of Aluminum from Sodium Carbonate Solution by Activated Carbon Fibers. Ind. Eng. Chem. Res. 2013, 52, 14449-14455. [CrossRef]

49. Li, H.Y.; Li, N.J.; Chen, D.Y. Polyethylene imine-grafted ACF@BiOI ${ }_{0.5} \mathrm{Cl}_{0.5}$ as a recyclable photocatalyst for high-efficient dye removal by adsorption-combined degradation. Appl. Surf. Sci. 2017, 403, 80-88. [CrossRef]

50. Cihanoğlu, A.; Gündüz, G.; Dükkancı, M. Degradation of acetic acid by heterogeneous Fenton-like oxidation over iron-containing ZSM-5 zeolites. Appl. Catal. B Environ. 2015, 165, 687-699. [CrossRef] 
51. Aleksić, M.; Kušić, H.; Koprivanac, N.; Leszczynska, D.; Božić, A.L. Heterogeneous Fenton type processes for the degradation of organic dye pollutant in water-The application of zeolite assisted AOPs. Desalination 2010, 257, 22-29. [CrossRef]

52. Gonzalez-Olmos, R.; Kopinke, F.D.; Mackenzie, K. Hydrophobic Fe-zeolites for removal of MTBE from water by combination of adsorption and oxidation. Environ. Sci. Technol. 2013, 47, 2353-2360. [CrossRef] [PubMed]

53. Zeng, Z.Q.; Zou, H.K.; Li, X.; Arowo, M.; Sun, B.C.; Chen, J.F.; Chu, G.W.; Shao, L. Degradation of phenol by ozone in the presence of Fenton reagent in a rotating packed bed. Chem. Eng. J. 2013, 229, 404-411. [CrossRef]

54. Duesterberg, C.; Mylon, S.; Waite, T. PH effects on iron-catalyzed oxidation using Fenton's reagent. Environ. Sci. Technol. 2008, 42, 8522-8527. [CrossRef]

55. Chen, X.; Ma, W.H.; Li, J.; Wang, Z.H.; Chen, C.; Ji, H.W.; Zhao, J.C. Photocatalytic oxidation of organic pollutants catalyzed by an iron complex at biocompatible $\mathrm{pH}$ values: Using $\mathrm{O}_{2}$ as main oxidant in a Fenton-like reaction. J. Phys. Chem. C 2011, 115, 4089-4095. [CrossRef]

56. Cuartero, M.; Crespo, G.; Cherubini, T.; Pankratova, N.; Confalonieri, F.; Massa, F.; Tercier-Waeber, M.; Abdou, M.; Schäfer, J.; Bakker, E. In situ detection of macronutrients and chloride in seawater by submersible electrochemical sensors. Anal. Chem. 2018, 90, 4702-4710. [CrossRef]

57. Xu, H.D.; Wang, D.; Ma, J.; Zhang, T.; Lu, X.H.; Chen, Z.Q. A superior active and stable spinel sulfide for catalytic peroxymonosulfate oxidation of bisphenol S. Appl. Catal. B Environ. 2018, 238, 557-567. [CrossRef]

58. Page, S.E.; Sander, M.; Arnold, W.A.; McNeill, K. Hydroxyl radical formation upon oxidation of reduced humic acids by oxygen in the dark. Environ. Sci. Technol. 2012, 46, 1590-1597. [CrossRef]

59. Zuorro, A.; Lavecchia, R.; Monaco, M.M.; Lervolino, G.; Vaiano, V. Photocatalytic degradation of azo dye Reactive Violet 5 on Fe-doped titania catalysts under visible light irradiation. Catalysts 2019, 9, 645. [CrossRef]

(C) 2020 by the authors. Licensee MDPI, Basel, Switzerland. This article is an open access article distributed under the terms and conditions of the Creative Commons Attribution (CC BY) license (http://creativecommons.org/licenses/by/4.0/). 